\title{
A (In)Visibilidade de Pessoas com Deficiência Visual nas Ciências Exatas e Naturais: Percepçóes e Perspectivas ${ }^{1,2}$ \\ The (In)Visibility of Visually Impaired People in SCience, Technology, Engineering, and Mathematics: Perceptions and Perspectives
}

\author{
Carolina Santos BONFIM ${ }^{3}$ \\ Gérson de Souza MÓL ${ }^{4}$ \\ Bárbara Carine Soares PINHEIRO5
}

\begin{abstract}
RESUMO: Neste estudo, de abordagem qualitativa, buscamos aduzir elementos relacionados à (in)visibilidade de pessoas com deficiência visual em cursos de Ciências Exatas e Naturais. A invisibilidade nesses cursos, temática pouco explorada até entâo, constitui uma barreira a ser superada para garantir o ingresso e a permanência desse público. Assim sendo, dialogamos com oito pessoas com deficiência visual em diferentes níveis do Ensino Superior, com formaçóes diversas, de variadas regióes do Brasil, para relatar, por meio de entrevistas semiestruturadas, suas percepçóes e perspectivas. Os dados foram analisados de acordo com pressupostos da análise de conteúdo de Bardin. Estabelecemos quatro categorias de análise que se inter-relacionam: "marcas do capacitismo nas Ciências Exatas e Naturais", "escolha do curso", "adaptação e acessibilidade”, "o papel do professor e aspectos formativos". Concluímos que a ausência de pessoas com deficiência visual nesses cursos mais tem a ver com as formas como essa condição é tratada do que com alguma inaptidão imputada à perda de visão.
\end{abstract}

PALAVRAS-CHAVE: Deficiências da visão. Ensino Superior. Educação Especial. Ensino de Ciências.

ABSTRACT: In this paper, of a qualitative approach, we sought to adduce aspects of the (in)visibility of visually impaired people in Science, Technology, Engineering, and Mathematics (STEM). The invisibility in these courses, a theme poorly addressed so far, constitutes a barrier to be surpassed to assure these people admission and stay. Thus, we interviewed eight people with a visual impairment at different levels of Higher Education and courses, from different regions of Brazil, to report their perspectives and perceptions through semi-structured interviews. The data were analyzed according to the assumptions of Bardin's content analysis. We established four inter-related categories "marks of ableism in STEM", "course choice", "adaptation and accessibility", and "teachers' role and formative aspects". We concluded that the absence of visually impaired people in these courses regards how people deal with disabilities more than the ineptitudes related to vision loss.

KEYWORDS: Visual impairment. Higher Education. Special Education. Science teaching.

\section{INTRODUÇÁO}

O direito à educação é garantido por lei, como estabelecido pela Constituição Federal do Brasil (1988). Embora seja um direito de todos, foi preciso que fosse instituída a Lei Brasileira de Inclusão da Pessoa com Deficiência (Lei no 13.146, de 6 de julho 2015), "destinada a assegurar e a promover, em condiçóes de igualdade, o exercício dos direitos e das liberdades

\footnotetext{
${ }^{1}$ https://doi.org/10.1590/1980-54702021v27e0220

${ }^{2}$ Este artigo decorre de pesquisa financiada pela Fundação de Amparo à Pesquisa do Estado da Bahia - FAPESB (Processo 2852/2018 e 1158/2018 - bolsista técnico).

${ }^{3}$ Pesquisadora autônoma. Doutoranda em Educação em Ciências pela Universidade de Brasília (UnB). Brasília/Distrito Federal/ Brasil. E-mail: carol.sb88@gmail.com. ORCID: https://orcid.org/0000-0001-8271-4098

${ }^{4}$ Doutor em Química, Professor do Instituto de Química e dos Programas de Pós-Graduação em Educação em Ciências da Universidade de Brasília (UnB) e Pós-Graduação em Educação em Ciências e Matemática da Rede Amazônica de Educação em Ciências e Matemática (REAMEC). Brasília/Distrito Federal/Brasil. E-mail: gersonmol@gmail.com. ORCID: https://orcid. org/0000-0002-1964-0513

${ }^{5}$ Doutora em Ensino, Filosofia e História das Ciências, Professora do Instituto de Química e do Programa de Pós-Graduação em Ensino, Filosofia e História das Ciências da Universidade Federal da Bahia (UFBA). Salvador/Bahia/Brasil. E-mail: soarespinheirob@gmail.com. ORCID: https://orcid.org/0000-0001-6899-8485
} 
fundamentais por pessoa com deficiência, visando à sua inclusão social e cidadania” (p. 8). Em se tratando de Ensino Superior, as pessoas com deficiência visual vêm enfrentando situaçóes muito desconfortáveis e pouco inclusivas. Apesar dos avanços alcançados pela legislação, como a aprovação da Lei $\mathrm{n}^{\circ}$ 13.409, de 28 de dezembro de 2016, estabelecendo que pessoas com deficiência façam parte dos programas de cotas de instituiçóes federais, o que resultou no aumento de matrículas (Pereira et al., 2020), ainda é muito complicado para uma pessoa com deficiência visual cursar uma faculdade, sendo poucos/as os/as que conseguem finalizar os cursos (Selau \& Damiani, 2016; Selau et al., 2017).

Pensando nas dificuldades que alunos/as com deficiência visual enfrentam nas universidades, Selau et al. (2017) expõem uma série de obstáculos, que vão desde a negação de que possam aprender conteúdos científicos, a ausência de comunicação entre professores e alunos, até a falta de interesse em trabalhar pedagogicamente com eles. Esse quadro agrava-se ao considerarmos os cursos de Ciências Exatas e Naturais (CEN), cuja presença de pessoas com deficiência visual é ainda menos expressiva. Dados extraídos do Censo da Educação Superior apontam que aproximadamente 20\% estão matriculados nesses cursos (Instituto Nacional de Estudos e Pesquisas Educacionais Anísio Teixeira [INEP], 2019). Ademais, estudos indicam a urgência da realização de discussões relacionadas à inclusão de pessoas com deficiência visual no Ensino Superior no contexto das Ciências Exatas e Naturais (Camargo, 2012; Silva \& Camargo, 2018). Do mesmo modo, as revisóes de Neres e Corrêa (2018), Santos et al. (2020), Silva e Bego (2018) e Uliana e Mól (2017) corroboram a incipiência de estudos que visam a depreender o que leva à invisibilidade desses sujeitos nesses cursos, o que justifica a investigação aqui proposta.

Dito isso, este estudo busca aduzir elementos relacionados à (in)visibilidade de pessoas com deficiência visual em cursos de Ciências Exatas e Naturais, sob a perspectiva de oito sujeitos com deficiência visual em diferentes níveis do Ensino Superior, com um amplo espectro de formaçóes obtidas em diferentes regióes do Brasil. Consideramos que a ideia de (in) visibilidade se refere à miríade de situaçóes que tornam os sujeitos "invisíveis", abrangendo desde a falta de identificação, o conhecimento sobre quem são, quais suas demandas, como podem ser auxiliados, se tem seus direitos assegurados, até a sua ausência nesses cursos (André \& Ribeiro, 2018; Capelli et al., 2020). Por meio desta pesquisa, evidenciamos aspectos até então não discutidos no âmbito das CEN, visando a superação de posturas capacitistas arraigadas, sendo o capacitismo, segundo Vendramin (2019), uma "leitura que se faz a respeito de pessoas com deficiência, assumindo que a condição corporal destas é algo que, naturalmente, as define como menos capazes" (p. 17). Essas posturas excludentes podem dificultar a permanência e, ao mesmo tempo, o interesse de pessoas com deficiência visual por esses cursos.

\section{Método}

Para responder à questão da pesquisa, a saber: De que maneira pessoas com deficiência visual percebem suas ausências em cursos de Ciências Exatas e Naturais?, optamos pelo método qualitativo, já que abarca a complexidade e a singularidade deste estudo. A natureza do objeto em destaque, por si só, remete à valorização na apreensão dos sentidos do fenômeno, tomando como ponto de partida o significado atribuído pelos partícipes (Chizzotti, 2014). 
A pesquisa foi aprovada pelo comitê de ética (CAAE: 94734418.0.0000.5531) e realizada na Universidade Federal da Bahia (UFBA), em colaboração com a Universidade de Brasília (UnB) e com o Núcleo de Apoio à Inclusão do Aluno com Necessidades Educacionais Especiais da UFBA (NAPE-UFBA). Para a realização das entrevistas, partimos de um questionário previamente elaborado, composto por sete perguntas abertas, abrangendo três temas: perfil dos participantes, vivência no Ensino Superior e ausência de pessoas com deficiência visual nas Ciências Exatas e Naturais. Três entrevistas ocorreram presencialmente (antes da pandemia da COVID-19) e cinco foram realizadas remotamente, em função da pandemia. Todas as entrevistas aconteceram individualmente e duraram em média uma hora.

Focamos, principalmente, nos relatos dos/as participantes cujas vivências têm se dado em graduaçóes envolvendo Ciências Exatas e Naturais. Em momento oportuno, apoderamo-nos das percepçóes de participantes para investigar os motivos pelos quais não optaram em seguir carreiras nas áreas de CEN. Além disso, esses sujeitos possuem impressóes sobre os cursos de CEN mesmo sem cursá-los, muitas vezes formadas a partir de suas vivências cotidianas. Todos os sujeitos já apresentavam deficiência visual antes de ingressar no Ensino Superior.

A referência aos participantes foi feita por nomes fictícios estabelecidos em ordem alfabética. As falas foram registradas com o auxílio de um gravador de áudio e transcritas por meio da combinação de dois softwares (Google Docs e VB-CABLE Virtual Audio Device ${ }^{\oplus}$ ). Realizamos as revisóes e as correçóes necessárias nas transcriçóes devido às imprecisóes do método automatizado e dos erros de português, procurando preservar os significados e a linguagem coloquial, característica da oralidade.

Para o exame dos dados coletados, inspiramo-nos em pressupostos da análise de conteúdo de Bardin (2011), tanto para a pré-análise das transcrições quanto para a exploração e a intepretação das temáticas levantadas. Consideramos fatores como frequência, direção favorável, neutra e desfavorável e presença de duas ou mais unidades de registro em uma dada unidade contextual (concorrência) para o estabelecimento das categorias. As Categorias 1, 3 e 4 emergiram da leitura flutuante das entrevistas transcritas. Já a Categoria 2 foi determinada aprioristicamente em decorrência das perguntas e, consequentemente, de seu tema, que redimensionaram os aspectos de interesse.

\subsection{CONHECENDO OS/AS PARTICIPANTES}

Para caracterizar os/as participantes, levamos em consideração o tipo de deficiência visual e seus estágios, com base em seus relatos. Desse modo, consideramos como se identificam (cegueira ou baixa visão), além da forma com a qual adquiriram essa condição, pois suas experiências manifestam-se de formas diferenciadas. No caso da cegueira, se for congênita, as experiências não se baseiam na visão; já aqueles que adquiriram cegueira guardam memórias das experiências vividas quando enxergavam (Almeida \& Araújo, 2013; Fernandes et al., 2017).

Outro ponto sobre os/as participantes alude à condição e à forma como a deficiência visual é vivenciada, uma vez que os contextos social, psicológico e familiar influenciam o comportamento frente à deficiência. Mesmo que possamos identificar características comuns entre as pessoas com deficiência visual, sobretudo no que se refere às suas percepçóes, o desenvolvi- 
mento de cada uma delas é singular, não diferindo dos videntes (Nunes \& Lomônaco, 2010). Os perfis dos/as participantes estão sintetizados no Quadro 1.

\section{Quadro 1}

Perfil dos alunos com deficiência visual (DV) entrevistados.

\begin{tabular}{|l|l|l|l|}
\hline \multicolumn{1}{|c|}{ Nome } & \multicolumn{1}{|c|}{ Tipo de DV } & \multicolumn{1}{c|}{ Causa } & \multicolumn{1}{c|}{ Curso e estágio } \\
\hline Amarante & Cegueira adquirida & Glaucoma & Produçáo Cultural (em andamento) \\
\hline Bebeto & Cegueira adquirida & Glaucoma & Museologia (em andamento) \\
\hline Cícero & Cegueira adquirida & Glaucoma & Ciências Sociais (em andamento) \\
\hline Daniela & Baixa visão congênita & Glaucoma congênito & Biologia (finalizado) \\
\hline Ellen & Cegueira adquirida & Retinose pigmentar & Engenharia Química (finalizado) \\
\hline Fábio & Cegueira congênita & Acidente & Comunicação Social (finalizado) \\
\hline Gabriel & Baixa visão congênita & Catarata congênita & Química Industrial (em andamento) \\
\hline Henrique & Cegueira adquirida & Uveíte crônica & $\begin{array}{l}\text { Análise de sistemas, Mestrado em Ciências } \\
\text { Naturais (em andamento) }\end{array}$ \\
\hline
\end{tabular}

\section{Resultados E Discussão}

A análise crítica dos dados está dividida em quatro categorias, tratadas na sequência:

(i) marcas do capacitismo nas Ciências Exatas e Naturais, (ii) escolha do curso, (iii) adaptação e acessibilidade e (iv) papel do professor e aspectos formativos.

\subsection{Marcas do capacitismo nas Ciências Exatas e Naturais}

A percepção de que as pessoas com deficiência visual, por não apresentarem o atributo da visão, seriam "menos capazes" de frequentar cursos de CEN predomina no imaginário coletivo dessas áreas, sem nem mesmo haver um questionamento ou uma reflexão do porquê isso é tão naturalizado. Quando esse tipo de pensamento parte de docentes, isso pode condicionar as pessoas com deficiência visual a não buscarem esses cursos (Regiani \& Mól, 2013); é, assim, um comportamento segregacionista. Tal situaçáo é exemplificada na fala de Ellen ao mencionar que "o professor não aceita a presença de pessoas com deficiência visual em determinados cursos, especialmente em determinados cursos nas áreas de exatas e engenharias, e uma quantidade surpreendente de pessoas [...] não esconde muito bem essa opiniāo". Gabriel ainda acrescentou que as pessoas com deficiência visual não são estimuladas a atuarem nessas áreas:

Os deficientes [sic] não são estimulados a atuar na área de exatas. Por exemplo, eu falo por mim, eu tenho que estudar em dobro, além de tirar uma nota boa pra provar pro sujeito que não me conhece que eu sou capaz. (Gabriel)

Ao tomarem como exemplo a Química, Regiani e Mól (2013) argumentam que tal quadro estaria ligado à presunção de admitir que, para "ser químico/a", o/a discente com deficiência visual precisaria ser hábil em laboratório, inclusive para aprender determinados conceitos científicos. Isso é respaldado no depoimento de Ellen, que ouviu de um professor que "uma pessoa que não consegue fazer determinado procedimento no laboratório, obviamente, não 
estaria habilitada pra ser uma química”. Em virtude de posturas excludentes como essa, Ellen se viu obrigada a mudar do curso de Química para Engenharia Química.

A “incapacidade” conferida às pessoas com deficiência visual não somente as condicionam a optarem por determinados cursos, como as fazem pensar que são "menos capazes". Essa condição passa a ser vista como uma desvantagem, como foi ressaltado no depoimento de Fábio:

Além das pessoas não acreditarem [no nosso potencial], ainda tem algumas pessoas com deficiência que de tanto ouvirem: "ah, você não dá conta", "ah, você não pode", a pessoa vai colocando aquilo na cabeça e aí talvez o motivo de não ter tantas pessoas com deficiência visual nas áreas de Ciências Naturais. (Fábio)

Não raramente, condições adversas enfrentadas também fora da universidade culminam no trancamento ou mesmo na desistência dos cursos. Essa situação não é incomum entre os participantes, visto que quase todos tiveram de afastar-se do curso por algum tempo. Esse é o caso de Gabriel, que precisou trancar o curso de Química Industrial: "eu moro num ambiente estudantil, como eu falei anteriormente, eu não sou da capital e juntando à pressão universitária com o ambiente fora de domicílio, sem o apoio da família, tudo isso contribuiu [para o trancamento do curso]". Gabriel mencionou questóes, infelizmente, recorrentes, como a falta do apoio familiar, as condiçôes financeiras e a pressão emocional decorrente do estresse de cursar uma Graduação.

Por parte dos colegas de turma, principalmente nas aulas de laboratório, também são adotadas posturas excludentes, por exemplo, quando não aceitam trabalhar em dupla (ou em grupo) com alunos/as cegos/as ou com baixa visão, ou quando aceitam e não os/as deixam executar os procedimentos. Outra forma de executar as atividades de laboratório é por meio do auxílio de tutores ou monitores. Entretanto, não raramente, os tutores apresentam suas próprias dificuldades: falta de formação, são alunos/as de Graduação sem preparação, que, muitas vezes, nunca lidaram com situaçóes semelhantes, obstáculos também relatados por Fernandes e Costa (2015). Ademais, são experiências relatadas por Mariano e Regiani (2015), assim como por Ellen e Henrique, os quais ilustraram o comportamento de colegas e tutores em aulas práticas:

Se eu não tivesse tido a ajuda de um amigo que se voluntariou, na verdade, se colocou como monitor da disciplina no geral, que praticamente me ajudou em quase todos os experimentos, eu talvez não tivesse conseguido passar nessa disciplina, não por não saber os princípios, [...], mas por causa disso [náo executar as práticas]. (Ellen)

Pegaram uma aluna que se candidatou e deram uma bolsa pra ela poder ser minha monitora, mas ela era aluna da própria turma. Entáo assim, isso também gerava algumas dificuldades, porque ao mesmo tempo que ela tinha que me auxiliar, ela também tinha que prestar a atenção pra ela também, não considero que foi a soluçáo mais adequada. (Henrique)

Amarante ressaltou "o preconceito que, de antemão, as pessoas dizem para essa pessoa: 'onde já se viu que você vai trabalhar no laboratório?’". Ellen ainda relatou: "Foi ficando cada vez mais claro que as experiências em laboratórios eram impossíveis pra mim”. Cícero disse: "Eu, especificamente, não vejo condição nenhuma para uma pessoa que não tem a visão ter uma produção científica em termos laboratoriais". 
A falta de reflexão sobre a dependência da visão nesses cursos, inclusive da exclusão de pessoas com deficiência visual em ambientes de laboratório, e a postura discriminatória de certos professores e colegas de turma são indicativos do capacitismo. Os discursos e as açóes de docentes em ambiente de sala de aula conferem uma falsa noção de sucesso na inclusão de pessoas com deficiência no sistema educacional, desde o Ensino Básico, desconsiderando a retenção e o abandono (Camargo \& Paes de Carvalho, 2019). Apesar de incorporado nos discursos e nas açóes de professores e de alunos dos cursos de CEN, o capacitismo é uma temática pouquíssimo abordada, mesmo no âmbito do Ensino de Ciências. Uma consulta nos principais periódicos de Ensino de Ciências (Investigaçôes em Ensino de Ciências; Ciência \& Educação; Revista Pesquisas em Educação em Ciências; Ensaio: Pesquisa em Educação em Ciências; e Alexandria) mostrou a ausência de publicaçóes que tratem dessa temática.

O fenômeno do capacitismo deriva, principalmente, da concepção de normatização social que impóe uma noçáo de homogeneidade dos corpos, pois o sujeito náo pode destoar dos demais (Camargo \& Paes de Carvalho, 2019; Mazzotta \& D’antino, 2011), do histórico de eugenia e, recentemente, do neoliberalismo (Brown, 2005; Vendramin, 2019). As pessoas embasam-se na aparência para rotular quem é cego ou quem apresenta baixa visão como seres "menos humanos e menos capazes" para, consequentemente, segregá-los. É comum que cegos se sintam invisíveis em alguma situação (Selau et al., 2017) ou em algum momento do curso nas áreas de CEN, fato relatado por Gabriel: "em alguns momentos, eu sou um sujeito invisível lá no centro de tecnologia da universidade”, e por outros participantes. Invisibilidade que decorre, muitas vezes, da indiferença, como enfatizou Cícero: "a indiferença por parte dos colegas, a falta de você puxar um assunto, uma conversa, você interagir”.

As pessoas com deficiência são geralmente tratadas com atitudes baseadas em invisibilidade e hipervisibilidade, reduzidas a estereótipos estigmatizados e socialmente construídos, como os discursos da superação (herói/heroína) e da caridade (coitado/a), de acordo com Vendramin (2019). Por invisibilidade, a autora considera açóes como desperceber ou desmerecer as pessoas com deficiência, muitas vezes por provocarem desconforto em quem se comporta dessa maneira, situaçóes discutidas também neste estudo. Já a hipervisibilidade dá-se quando a deficiência sobrepõe as características que determinam a identidade, por exemplo: a pessoa é mais conhecida como "fulano/a, o/a cego/a" do que por suas qualidades. A permanência das pessoas com deficiência visual em cursos de Graduação em CEN é marcada pela invisibilidade, assim como a escolha pela carreira está ligada à ideia de superação, como discutiremos a seguir.

\subsection{ESCOLHA DO CURSO}

Com relação à escolha por determinado curso, notamos não ter vinculação com a condição de pessoa com deficiência visual, sendo justificada, normalmente, por dois motivos: o bom desempenho nas disciplinas do Ensino Médio, que tem conexão direta com os cursos escolhidos, por exemplo: o bom desempenho em Química fez com que Ellen escolhesse Química, situação semelhante em muitos casos de videntes; ou se espelhavam na trajetória de pessoas com deficiência visual bem-sucedidas em determinados cursos. Ressaltamos, assim, a importância da representatividade em carreiras de CEN. Nesse âmbito, Cícero relatou: "Até então, eu ainda não conheço alguém na minha condição de pessoa sem visão para esse desen- 
volvimento [trabalhos laboratoriais]". Fábio seguiu na mesma direção: "Eu tive muito a influência de colegas [com deficiência visual] que se tornaram professores, por exemplo, outros que se tornaram psicólogos, e assim sucessivamente, aquilo 'me deu um gás', eu pensei comigo: se eles conseguiram, por que eu não posso?".

Se o/a aluno/a com deficiência visual não encontra ou nunca ouve falar de cegos/as ou de pessoas com baixa visão que são cientistas, como irá pensar na possibilidade de seguir a carreira? Do mesmo modo, como professores passarão a acreditar, de fato, na possibilidade de pessoas com deficiência visual serem cientistas? Exemplos contemporâneos, como os da astrônoma porto-riquenha Wanda Díaz-Merced e do professor brasileiro de Física Eder Pires de Camargo, episódios históricos, como de Johannes Kepler (1571-1630) e John Dalton (17661844), que permitem explorar a trajetória de cientistas com deficiência visual, podem proporcionar um incentivo aos/às discentes com deficiência visual para ingressar e permanecer nessas áreas, além da quebra de estereótipos.

Sobre o interesse pelas Ciências, Daniela fez um questionamento interessante: "Se a pessoa não tem acesso, como ela vai saber que aquilo é o que ela gosta?”. Isso remete à invisibilidade nessas profissóes estar mais relacionada à falta de acesso quando não se faz adaptaçóes e não se proporciona um suporte específico nas disciplinas de Ciências, o qual pode estar vinculado à falta de preparo de professores/as e da escola como um todo.

Amarante sugeriu que a baixa qualificação das pessoas com deficiência visual pode levá-las a não optar por esses cursos: "A baixa qualificação, porque uma pessoa cega, na média, ela é muito menos qualificada do ponto de vista dos estudos antecedentes". Por certo que, devido a uma conjunção de fatores, as pessoas com deficiência estão em situação de desigualdade quanto ao acesso à educação. Gabriel, além de mencionar a baixa qualificação, destacou a falta de preparo das escolas e dos/as professores/as, como alguns desses fatores:

A dificuldade na base, a gente tem um sério problema na base. O deficiente [sic] faz um [Ensino] Fundamental péssimo, um Ensino Médio péssimo, porque os professores realmente não são preparados pra isso, por isso que a maioria opta pela área de Humanas que teoricamente é mais fácil. (Gabriel)

Já Bebeto realçou a elevada concorrência para o ingresso nos cursos de CEN, principalmente para as engenharias: "Acho que esses componentes, eles são muito procurados, se o score [nota] é muito alto para entrar", o que leva à procura por áreas menos concorridas. Por essas razóes que a política de cotas se faz tão necessária. Mesmo com a implementação da Lei de Cotas para Pessoas com Deficiência (Lei n 13.409 , 2016), não se nota um significativo aumento nas matrículas em cursos de CEN em comparação com os demais. A "falta de base" é alegada recorrentemente por professores/as de cursos fora das Ciências Humanas (Capelli et al., 2020).

Os/as entrevistados/as que cursam/cursaram áreas de Ciências Exatas e Naturais (Daniela, Ellen, Gabriel e Henrique) acrescentaram, além dos motivos supracitados, que se sentiam mais desafiados e acreditavam que contribuíam mais para essas áreas, no sentido de torná-las mais acessíveis, servindo de exemplo para outras pessoas com deficiência visual, o que também evidencia a importância da representatividade: 
Eu sou uma pessoa que defende muito isso, de que se a gente conhecer as pessoas que conseguiram chegar lá, apesar de todas as barreiras, isso vai motivar mais pessoas a chegar e quanto mais pessoas, mais a gente consegue ir descontruindo as barreiras. (Henrique)

Inserida no capacitismo, temos a ideia de superação. A pessoa com deficiência é vista como alguém que precisa superar as adversidades impostas por um mundo "normal" e quem supera é alçado ao status de herói, servindo de exemplo para os demais (Vendramin, 2019). Entretanto, devemos compreender que qualquer ser humano possui limitaçóes, mas, nem por isso, suas trajetórias são menos admiráveis (Silva et al., 2018). Reconhecer os limites e, principalmente, as potencialidades das pessoas com deficiência visual náo pode ser confundido com o mito da superação ou do heroísmo, "uma vez que já há heroísmo suficiente na vida de qualquer pessoa, seja ela uma pessoa com deficiência ou não" (Silva et al., 2018, p. 65). O mito da superação da deficiência está enraizado no discurso dos partícipes. Por achar que seja um desafio maior seguir as áreas de Ciências Exatas e Naturais, muitas pessoas com deficiência visual desistem, sequer tentam. Claro que a representatividade tem a sua importância, mas ela não é um fim, ela é um meio. Assim sendo, devemos fomentar a representatividade, sem cair no discurso da hipervisibilidade.

\subsection{AdAPTAÇÁo E ACESSIBILIDADE}

As pessoas com deficiência percebem sua condição a partir de adequaçóes e de concessōes feitas para adaptá-las, passando a compreender que o mundo não é feito para elas, afirma Vigotski (2011). O autor argumenta que "a educação surge em auxílio, criando técnicas artificiais, culturais, um sistema especial de signos ou símbolos culturais adaptados às peculiaridades da organização psicofisiológica" (p. 867). Consideramos que a maneira pela qual as pessoas com deficiência visual percebem que sua posição é inferiorizada se dá pelo que chamamos na atualidade de "adaptação".

De modo geral, os participantes relataram, inicialmente, ter dificuldades de locomoção na universidade, algo compreensível, haja vista que ainda não conheciam esses espaços, precisando da "ajuda" de outros estudantes para poderem locomover-se. Algumas instituiçóes contam com núcleos de apoio especializados, que disponibilizam tutores para auxiliar no processo inicial de mobilidade. A importância de equipes preparadas para possibilitar acessibilidade às pessoas com deficiência visual vai além da locomoção, pois, da mesma forma, garante que esse público se sinta acolhido e como parte efetiva da comunidade universitária. $\mathrm{O}$ depoimento de Ellen sobre quando passou a frequentar o núcleo de apoio demonstrou isso: "Eu me sentia, obviamente, mais integrada, conhecendo pessoas com dificuldades parecidas e iniciativas que ajudavam a gente."

André e Ribeiro (2018) alertam que a falta de Atendimento Educacional Especializado (AEE) nas Instituições de Ensino Superior (IES) decorre da inexistência de uma cultura de acessibilidade. É primordial, portanto, que discentes com deficiência visual sejam reconhecidos em todos os sentidos, até para que se cumpram as leis, uma vez que têm direito à prestaçáo de serviço especializado nas universidades. Para isso, faz-se necessário que conheçam seus direitos. Tanto Ellen quanto Henrique relataram que parte das dificuldades iniciais ao ingressarem na 
faculdade decorreu do fato de serem muito novos e não saberem seus direitos perante a instituição. Esse fator reforça a importância dos núcleos de atendimento aos/às estudantes público-alvo da Educação Especial, pois foi por meio dessas dificuldades que os/as partícipes passaram a ter ciência de seus direitos.

Uma insatisfação recorrente dos/as entrevistados/as refere-se ao atraso na adaptação de materiais das disciplinas, o que tem ocorrido por dois motivos: quando os professores precisam realizar a adaptação ou quando núcleos não têm membros o suficiente ou tecnologias assistivas apropriadas para preparar os materiais. Assim, o/a aluno/a vai para a aula, muitas vezes, sem ter lido o material, o que reflete no seu interesse e em seu desempenho. Para agravar, Silva e Camargo (2018) salientam que os ledores de tela não fazem audiodescrição de imagens, tabelas, gráficos, modelos ou conteúdos geométricos, ferramentas frequentemente utilizadas nas CEN. Diante disso, indicamos que é necessário contratar tutores ou profissionais habilitados em audiodescrição para transcrever os materiais ou buscar outros meios de promover a mediação didática, sem depender de materiais adaptados, como sugerido por Henrique:

$\mathrm{Na}$ verdade, é uma descrição que foi resumida em diagrama ou modelo, ou seja, primeiro é uma descrição, é totalmente conceitual, só que aí pensando na pessoa que enxerga, alguém decide criar um diagrama para representar toda uma ideia. Entáo, assim, faz muito sentido pra quem enxerga, mas pra quem não enxerga, a descrição é muito mais adequada do que aquela imagem, aquele diagrama. (Henrique)

O forte uso de representações visuais em disciplinas desses cursos leva os professores a pensarem que essa é a única forma de aprender tais conteúdos, desconsiderando que essas representaçóes são produzidas para facilitar o aprendizado do aluno vidente e que, não necessariamente, precisam ser adaptadas ao/à aluno/a cego/a. Como Henrique chamou atenção, antes de serem modelos ou diagramas, são descrições conceituais, que dependem da linguagem científica.

Nas aulas práticas estão concentrados os grandes dilemas por serem palcos de muitos embates dos processos inclusivos, principalmente no que tange à adaptação e à acessibilidade para ambos os públicos (cegos e com baixa visão). Ellen mencionou que, devido à sua condição, não executava boa parte das atividades de laboratório: "Eu não era dispensada das aulas, eu tinha que continuar por lá, mas praticamente em todas as aulas experimentais eu não fazia muita coisa [...]". Gabriel também relatou que frequentava o laboratório, mas não executava as atividades:

Eu tento fazer o experimento sozinho, aí quando eu falo que estou com um problema todo mundo entra em pânico: "vai quebrar a vidraria!", e isso deixa o sujeito inibido. E aí, normalmente, os relatórios são em grupo, eles póem meu nome lá e fica tudo certo, mas não é o correto. (Gabriel)

Dessa forma, os/as alunos/as estão no ambiente, mas não se consideram parte dele, sentem-se excluídos/as das atividades práticas de laboratório. A falta de acesso a esses espaços de forma plena e em condição de igualdade, em relação aos/às videntes, prejudica a formação das pessoas com deficiência visual, fato apontado por Mariano e Regiani (2015).

Tendo em vista esses fatores, são inúmeras as possibilidades de inclusão de pessoas com deficiência visual nas aulas práticas, basta que haja um direcionamento nesse sentido. Adaptaçóes de botões para Braille, uso de termômetros sonoros, troca de sinais visuais por 
sinais sonoros e metodologias multissensoriais são estratégias que podem ser adotadas para tornar esses espaços mais acessíveis. $\mathrm{Na}$ atualidade, vemos que grande parte dos trabalhos em laboratórios são automatizados, em decorrência do aperfeiçoamento e da evolução dos equipamentos e das técnicas de análise (Eichler et al., 2018). Ainda, cientistas não trabalham sozinhos, abrindo possibilidade para que determinadas etapas e certos tipos de atividades científicas possam ser destinadas a pessoas com deficiência visual.

Outro elemento que caracteriza esses cursos é a linguagem matemática. A crença de que pessoas com deficiência visual têm dificuldade com Matemática se baseia em preconceitos. Dos/as alunos/as entrevistados/as que fizeram ou fazem cursos de Ciências Exatas e Naturais, todos/as afirmaram nunca ter dificuldades com cálculos matemáticos, como Daniela: "Genética, que é quase que a matemática da saúde [...], eu fui muito bem. Eu faço conta de cabeça”. A dificuldade está centrada no processo de adaptação dos cálculos. Mesmo os/as entrevistados/as que não atuam nessas áreas admitem que a dificuldade com Matemática é relativa à falta de acessibilidade e às barreiras atitudinais, como denotou Fábio: "No meu Ensino Médio, quando tinha alguma matéria de Matemática, eu também tinha sérios problemas". Tais problemas não eram oriundos do uso de cálculos, pois, segundo ele: "Os cálculos, perto da falta de acessibilidade, perto da incompreensão dos professores, são tranquilos”.

Carvalho et al. (2018), ancorados em Vigotski (1997), sinalizam que a utilização da linguagem matemática convencional pode prejudicar o processo de mediação, pois, para os softwares ledores de tela, os símbolos são incompreensíveis, sendo passível de gerar um sentimento de "fracasso" e um desestímulo por parte dos/as alunos/as. Contudo, Carvalho et al. (2018) pontuam que a acessibilidade não pode ser depreendida "como uma garantia de sucesso para o mecanismo de compensação, mas um importante passo em direção à 'super compensação”" (p. 430). Os autores recomendam a linguagem LaTeX como uma ferramenta potencial para a promoção à acessibilidade, considerando conhecimentos para os quais a compreensão depende de cálculos matemáticos. Esse recurso não é restrito a pessoas com deficiência visual, pois já era usado por videntes, o qual manifesta um caráter dialógico, favorecendo as relações entre alunos/as.

Regiani e Mól (2013) apontam que o processo de inclusão depende das características das disciplinas do curso, dado que algumas favorecem a inclusão, enquanto outras não. Corroborando essa ideia, Daniela relata que teve dificuldades severas com as disciplinas de Histologia e Botânica, devido à necessidade de examinar lâminas no microscópio, que, mesmo com o uso de lupa, não era possível.

A gente tentou adaptação com tela também, aumentando. Mas não teve uma adaptação que fosse suficiente pra eu entender algumas coisas, eu entendia o desenho, mas quando botava a lâmina em si eu náo sabia identificar, entendeu? A mesma coisa com as plantas [...], isso refletia no meu interesse, consequentemente nas minhas notas em Botânica. Em Histologia, não. Em Histologia, ela (a professora) fez adaptação de outras formas. Então, ela adaptava a nota com o que eu era capaz de fazer, porque eu tinha algum interesse ainda, mas Botânica eu fiquei muito frustrada, aí refletiu bastante na nota. (Daniela)

O processo de adaptação não necessariamente passa por criar modelos táteis, pois ele pode dar-se por outras formas. De acordo com Nunes e Lomônaco (2010), "embora o tato seja uma importante via de informação para o sujeito cego, obviamente não é a única" 
(p. 57). A adaptação pode dar-se por meio da flexibilização de avaliaçôes, como exemplificado nas falas de Daniela. Costa (2018) relata que uma das barreiras sistêmicas para a inclusão no Ensino Superior é a flexibilização dos processos avaliativos e as adaptaçóes curriculares. A partir das falas dos partícipes, percebemos que existe uma resistência nos cursos de CEN quanto à adaptação de avaliaçóes, especialmente as ocorridas em aulas práticas. Assim sendo, devemos considerar que a responsabilidade nessas adaptações não é única e exclusiva dos/das docentes aos/às quais devem ser oportunizadas melhores condiçóes de trabalho, formação específica e ação conjunta com o AEE das universidades.

\subsection{O PAPEL DO PROFESSOR E OS ASPECTOS FORMATIVOS}

Os discursos dos/as entrevistados/as transparecem o que pensam a respeito do papel do/a professor/a e dos processos formativos. Assim como o/a professor/a constrói percepçóes e articula saberes com a prática docente, os/as alunos/as formulam pensamentos de como deve ser um/a professor/a "ideal”. Isso fica claro na fala de Ellen:

Quando o professor é uma pessoa aberta e receptiva e um educador de verdade, ele não precisa da interferência de programas externos pra ouvir o aluno e tentar adaptar (aulas e materiais). Ele, na verdade, procura a ajuda desses programas (núcleos de apoio). Como em particular um dos meus professores procurou o núcleo ativamente, procurou recursos. Eu achei uma coisa louvável. (Ellen)

Um dos recursos disponíveis, para os quais Ellen chamou atenção em sua fala, são os núcleos de apoio, responsáveis por oferecer AEE nas IES. Segundo o $5^{\circ}$ parágrafo do Decreto $n^{\circ}$ 7.611, de 17 de novembro de 2011, "os núcleos de acessibilidade nas instituiçóes federais de educação superior visam eliminar barreiras físicas, de comunicação e de informação que restringem a participação e o desenvolvimento acadêmico e social de estudantes com deficiência”. A ação desses núcleos, além de romper barreiras atitudinais, pode trazer suporte educacional aos/ às discentes, dentro e fora de sala de aula, compartilhando uma responsabilidade que, muitas vezes, é atribuída unicamente aos/às professores/as.

Para lidar com alunos/as com deficiência visual nos cursos de CEN, são necessários saberes docentes específicos (Camargo, 2012), como saber vincular os conceitos científicos por meio de representaçóes que não dependam exclusivamente da visão; e, como apontam Paula et al. (2017), "saber trabalhar com a linguagem matemática; saber realizar atividades comuns aos alunos com e sem deficiência visual” (p. 874). Os autores também constatam que professores/as de Química devem discutir sobre a dependência da visão na abordagem de conceitos químicos, o que pode ser extrapolado para as CEN.

No entanto, o domínio desses saberes não pode ser limitante ao processo inclusivo, uma vez que uma das crenças é que professores/as devem, antes de tudo, ser preparados para depois iniciarem a inclusão (Griboski \& Alves, 2013). Isso é no mínimo contraditório se pensarmos que, há quase duas décadas, já existiam leis que reforçavam a necessidade de formar professores/as capacitados/as para o ensino inclusivo (Silva \& Mól, 2018). Em virtude desse despreparo e sabendo que a inclusão é um processo já iniciado, não devemos esperar que professores/as se sintam capacitados/as para, a partir daí, incluir. Ao contrário, essa formação pode 
e precisa ocorrer em paralelo à prática em sala de aula, mas, para isso, deve ser oferecida formação contínua. A qualificação profissional relativa à inclusão escolar demanda conhecimentos para além dos científicos, pois o/a professor/a deparar-se-á frequentemente com singularidades, ambiguidades e valores diferentes dos seus, exigindo o desenvolvimento de aptidóes para enfrentar a realidade do contexto inclusivo de ciências.

O problema é anterior a isso, pois já é enraizado que aprender CEN é difícil. Dessa maneira, a desmitificação de preconceitos como esse depende, também, em parte, do/a professor/a e está relacionada à sua concepção de ciência (Silva \& Mól, 2019). Uma ciência que se considera neutra e desconsidera a diversidade provavelmente excluirá o público-alvo da Educação Especial. As Ciências são, assim, resultado do empreendimento humano e, como tal, são feitas em um dado âmbito cultural e seus agentes estão, inevitavelmente, imersos nessa cultura.

Docentes têm assumido que é possível pessoas com deficiência visual se graduarem em cursos de CEN (Bohnert \& Mól, 2018; Mariano \& Regiani, 2015; Silva \& Mól, 2019; Veraszto et al., 2014). Todavia, como tornar isso factível? Além de promover uma mudança na concepção de ciência dos/as professores/as e colegas, uma série de medidas precisam ser adotadas pelas IES, como implantação e atuação ostensiva de núcleos de AEE, contratação de profissionais especializados, investimentos em infraestrutura (especialmente de laboratórios), formação continuada e promoção de programas voltados ao corpo discente. Bebeto relatou um episódio vivenciado por uma colega cega:

Eu conheci uma moça cega dentro da (Universidade), e que uma professora disse: "Ah, inclusão é muito fácil”, mas na teoria... Na prática, o buraco é mais embaixo. Desestimulou ela totalmente. E dentro da faculdade, eu acho que a experiência que eu tive da primeira graduação do bacharelado, me diz que a manutenção dessa trajetória sombria, sobretudo dentro desses cursos mais técnicos... Ela nasce mais dentro da universidade do que fora. (Bebeto)

Os depoimentos de Ellen e Bebeto sugerem que os cursos de Ciências Exatas e Naturais teriam uma forma característica de organizar-se e que grande parte das barreiras para a inclusão se deve às atitudes de professores/as desses cursos, os quais têm posturas mais capacitistas e segregadoras que os/as demais. Isso se dá principalmente quando o assunto é lidar com discentes público-alvo da Educação Especial, de tal modo que isso pode determinar o futuro do/a aluno/a, quando este/a se vê obrigado/a a largar ou a transferir-se de curso, fato ocorrido com Ellen. Dessa forma, os cursos de CEN teriam uma natureza mais fria, "sombria”, técnica e competitiva, o que dificultaria o processo de inclusão, como ressaltou Bebeto. Quem sabe, essa natureza "fria e sombria" esteja relacionada, também, à concepção de ciência prevalecente.

Ellen classificou os professores que não se envolviam com questões inclusivas como "neutros" e responsabilizou a excessiva carga de trabalho pelo não envolvimento. De fato, as exigências de produtividade na universidade relegam a docência a um segundo plano (Regiani \& Mól, 2013). Fica implícito, na colocação de Ellen, que tal envolvimento se trata de uma "ajuda" aos estudantes, quando deveria ser parte do trabalho do/a professor/a.

Eles (professores) não se negam a ajudar, mas eles, obviamente, querem reduzir o trabalho. Se necessitarem, eles acatam a determinação da universidade, mas não procuram nada fora dali. Uma pequena parte dos professores, que sáo pessoas excelentes, de fato ativamente procuram 
ajudar e se interessam pelo assunto [inclusão], encaram como uma oportunidade de aprendizado, um desafio novo. (Ellen)

Um dos maiores obstáculos para o aprendizado de alunos/as com deficiência visual centra-se na formação de professores, que, segundo Nunes e Lomônaco (2008), "precisam ter acesso aos materiais adaptados e ter condiçóes físicas e psicológicas para criarem as adaptaçóes necessárias ao ensino do aluno" (p. 135). No que concerne à formação inicial de professores/as de licenciatura em CEN no contexto da inclusão escolar, alertamos para a inserção de diretrizes nas disciplinas e nos planos de cursos para pôr em prática o que vem sendo discutido e elaborado na legislação e no campo especializado. A Grafia Química Braille para uso no Brasil poderia, por exemplo, tornar-se obrigatória nas licenciaturas, assim como já é a disciplina de Língua Brasileira de Sinais (Libras). Da mesma forma, disciplinas que abordem a Educação Especial poderiam ser instituídas nos currículos de licenciaturas. Por fim, sugerimos que, para a inclusão de alunos público-alvo da Educação Especial nos cursos de Ciências Exatas e Naturais, se cogite a formação contínua, no que diz respeito aos saberes vinculados à Educação Especial, de modo a estendê-la a professores/as que não possuem formação em licenciaturas.

\section{CONSIDERAÇÓES FinaIS}

Este estudo contribui com a literatura, dada a incipiência de pesquisas que visem a discutir a invisibilidade de pessoas com deficiência visual, sob sua perspectiva, especificamente em cursos de Ciências Exatas e Naturais. Consideramos que a baixa incidência de universitários/as cegos/as e com baixa visão nesses campos constituiu a principal dificuldade para o desenvolvimento desta pesquisa e de trabalhos futuros. A análise crítica dos depoimentos permitiu a identificaçấo do perfil dos/as estudantes que tanto buscam seguir carreira nas Ciências Exatas e Naturais quanto os que não buscam, bem como suas conquistas e os principais obstáculos que enfrentam, resultando em afastamento ou abandono dessas áreas, além de trazer à lume sugestóes que visem a superação dessas barreiras.

Assim como os/as estudantes com deficiência visual não têm se interessado por essas áreas devido a uma série de dificuldades enfrentadas, aqui discutidas, os cursos de CEN são marcados pelo capacitismo, fenômeno de natureza sociológica até então não abordado nesse âmbito. Percebemos que, nesses cursos, características específicas afetam a inclusão de discentes com deficiência visual, a saber: o laboratório ainda é entendido como restrito aos videntes disso decorre a resistência para adaptar aulas práticas e a recusa dos colegas para trabalhar com esses sujeitos. Além disso, há a necessidade de tutores ou monitores, os quais aconselhamos não serem colegas de turma. Outra barreira sistêmica de cursos de Ciências Exatas e Naturais refere-se à resistência em adaptar processos avaliativos.

A limitação para o não cumprimento de alguma tarefa não se centra no/a aluno/a com deficiência visual, mas na sociedade que não propicia meios para a sua inclusão. $\mathrm{Na}$ realidade, a limitação do/a aluno/a deveria mover o/a professor/a pensar em diferentes estratégias e não transferir sua responsabilidade para o/a aluno/a ou o ambiente, ao assumir, nesse caso, uma postura capacitista. Isso acontece também quando negam suas presenças nas aulas práticas de laboratório, 
ou os deixam "invisíveis" nesses espaços, "colocando-os lá” sem efetivamente participar das atividades. Ao pensarmos nessa problemática, os núcleos de AEE são de suma importância.

Pontuamos que existem outras vias de facilitar os processos inclusivos que não o uso de softwares de leitura e a adaptação de materiais tateáveis, corriqueiramente empregados nas Ciências Exatas e Naturais. Outras possibilidades pouco exploradas, como o aperfeiçoamento das descriçôes conceituais de conteúdos científicos, assim como as metodologias multissensoriais, que podem ser aplicadas às práticas de laboratório, constituem-se como alternativas viáveis e promissoras.

Este estudo demarca a importância de propiciarem-se políticas públicas e medidas institucionais que incentivem estudantes cegos/as e com baixa visão a interessarem-se, ingressarem e permanecerem em cursos de CEN, servindo também de ponto de partida para o desenvolvimento de futuras pesquisas. Para além de denunciar a invisibilidade, buscamos contribuir com a desconstrução de posturas capacitistas. Entender melhor a questão da invisibilidade de alunos/as com deficiência visual vai além da compreensão das razóes que levam à invisibilidade, pois demanda a investigação da importância da visão para a produção de conhecimento nessas áreas, bem como conhecer a percepção desses sujeitos a respeito dessas ciências e de cientistas, temas que serão abordados em trabalhos futuros.

\section{REFERÊNCIAS}

Almeida, T. S., \& Araújo, F. V. (2013). Diferenças experenciais entre pessoas com cegueira congênita e adquirida: uma breve apreciação. Revista Interfaces: Saúde, Humanas e Tecnologia, 1(3), 1-21.

André, B. P., \& Ribeiro, A. L. B. (2018). A invisibilidade de alunos com deficiência no Ensino Superior no norte fluminense. In G. S. Mól, \& D. C. F. Melo (Orgs.), Pessoas com deficiência no ensino superior: desafios e possibilidades (v. 2, pp. 62-73). Brasil Multicultural.

Bardin, L. (2011). Análise de conteúdo. Edições 70.

Bohnert, G. O. M., \& Mól, G. S. (2018). Uma proposta de ação formativa para professores de química na educação superior. In G. S. Mól (Org.), Pessoas com deficiência no Ensino Superior (v. 2, pp. 3651). Brasil Multicultural.

Brown, W. (2005). Edgework: critical essays on knowledge and politics. Princeton University Press.

Camargo, E. P. (2012). Saberes docentes para a inclusão do aluno com deficiência visual em aulas de Física. Editora Unesp.

Camargo, F. P., \& Paes de Carvalho, C. (2019). O direito à educação de alunos com deficiência: a gestão da política de educação inclusiva em escolas municipais segundo os agentes implementadores. Revista Brasileira de Educação Especial, 25(4), 617-634. https://doi.org/10.1590/s141365382519000400006

Capelli, J. C. S., Di Blasi, F., \& Dutra, F. B. S. (2020). Percepção de docentes sobre o ingresso de um estudante surdo em um campus universitário. Revista Brasileira de Educação Especial, 26(1), 85108. https://doi.org/10.1590/s1413-65382620000100006

Carvalho, J. C. Q., Couto, S. G., \& Camargo, E. P. (2018). A linguagem Latex e o ensino de Física para alunos com deficiência visual. Investigaçōes em Ensino de Ciências, 23(2), 424-438. http://dx.doi. org/10.22600/1518-8795.ienci2018v23n2p424

Chizzotti, A. (2014). Pesquisa qualitativa em ciências humanas e sociais. Vozes. 
Constituição Federal da República Federativa do Brasil. (1988). http://www.planalto.gov.br/ccivil_03/ Constituicao/Constituicao.htm

Costa, V. B. (2018). Reflexão docente sobre avaliação dos estudantes com deficiência no ensino superior. Revista Itinerarius Reflectionis, 14(1), 1-16. https://doi.org/10.5216/rir.v14i1.50593

Decreto $n^{o}$ 7.611, de 17 de novembro de 2011. Dispóe sobre a educação especial, o atendimento educacional especializado e dá outras providências. http://www.planalto.gov.br/ccivil_03/_ ato2011-2014/2011/decreto/d7611.htm

Eichler, T. Z. N., Eichler, M. L., \& Del-Pino, J. C. (2018). Estética e ensinagem na perspectiva da físicoquímica. REDEQUIM, 4(2), 173-193.

Fernandes, W. L., \& Costa, C. S. L. (2015). Possibilidades da tutoria de pares para estudantes com deficiência visual no Ensino Técnico e Superior. Revista Brasileira de Educação Especial, 21(1), 3956. http://dx.doi.org/10.1590/S1413-65382115000100004

Fernandes, T. C., Hussein, F. R. G. S., \& Domingues, R. C. P. R. (2017). Ensino de química para deficientes visuais: a importância da experimentação num enfoque multissensorial. Química Nova na Escola, 39(2), 195-203. http://dx.doi.org/10.21577/0104-8899.20160076

Griboski, C. M., \& Alves, D. O. (2013). A educação especial e as perspectivas da formação docente no contexto da educação inclusiva. In T. C. S. Cerqueira (Org.), Transdisciplinaridade e subjetividade: saberes e perspectivas docentes ( $1^{\text {a }}$ ed., pp. 67-77). Editora CRV.

Instituto Nacional de Estudos e Pesquisas Educacionais Anísio Teixeira. (2019). Censo da Educação Superior 2018. INEP/MEC.

Lei $n^{o}$ 13.146, de 6 de julho de 2015. Institui a Lei Brasileira de Inclusão da Pessoa com Deficiência (Estatuto da Pessoa com Deficiência). http://www.planalto.gov.br/ccivil_03/_ato2015-2018/2015/ lei/l13146.htm

Lei no 13.409, de 28 de dezembro de 2016. Altera a Lei $n^{\circ} 12.711$, de 29 de agosto de 2012, para dispor sobre a reserva de vagas para pessoas com deficiência nos cursos técnico de nível médio e superior das instituições federais de ensino. http://www.planalto.gov.br/ccivil_03/_Ato2015-2018/2016/ Lei/L13409.htm

Mariano, L. S., \& Regiani, A. M. (2015). Reflexôes sobre a formação e a prática pedagógica do docente de Química cego. Quimica Nova na Escola, 37(1), 19-25. http://dx.doi.org/10.5935/01048899.20150015

Mazzota, M. J. S., \& D’antino, M. E. F. (2011). Inclusão social de pessoas com deficiência e necessidades especiais: cultura, educação e lazer. Saúde e Sociedade, 20(2), 337-389. https://doi.org/10.1590/ S0104-12902011000200010

Neres, C. C., \& Corrêa, N. M. (2018). Análise dos artigos na área de deficiência visual publicados na Revista Brasileira de Educação Especial (1992-2017). Revista Brasileira de Educação Especial, $24(\mathrm{n}$. esp.), 153-166. https://doi.org/10.1590/s1413-65382418000400011

Nunes, S. S., \& Lomônaco, J. F. B. (2008). Desenvolvimento de conceitos em cegos congênitos: caminhos de aquisição do conhecimento. Psicologia Escolar e Educacional, 12(1), 119-138. https:// doi.org/10.1590/S1413-85572008000100009

Nunes, S. S., \& Lomônaco, J. F. B. (2010). O aluno cego: preconceitos e potencialidades. Revista Semestral da Associação Brasileira de Psicologia Escolar e Educacional, 14(1), 55-64. https://doi. org/10.1590/S1413-85572010000100006

Paula, T. E., Guimarães, O. M., \& Silva, C. S. (2017). Necessidades formativas de professores de Química para a inclusão de alunos com deficiência visual. Revista Brasileira de Pesquisa em Educação em Ciências, 17(3), 853-881. https://doi.org/10.28976/1984-2686rbpec2017173853 
Pereira, R. R., Faciola, R. A., Pontes, F. A. R., Ramos, M. F. H., \& Silva, S. S. C. (2020). Alunos com deficiência na Universidade Federal do Pará: dificuldades e sugestôes de melhoramento. Revista Brasileira de Educação Especial, 26(3), 387-402. https://doi.org/10.1590/1980-54702020v26e0087

Regiani, A. M., \& Mól, G. S. (2013). Inclusão de uma aluna cega em um curso de licenciatura em Química. Ciência \& Educação, 19(1), 123-134. https://doi.org/10.1590/S1516-73132013000100009

Santos, P. M. S., Nunes, P. H. P., Weber, K. C., \& Lima-Júnior, C. G. (2020). Educação inclusiva no Ensino de Química: uma análise em periódicos nacionais. Revista Educação Especial, 33, 1-19. http://dx.doi.org/10.5902/1984686X36887

Selau, B., \& Damiani, M. F. (2016). A conclusão da educação superior por cegos e a psicologia de Vygotski: a ponta do iceberg. Perspectiva, 34(3), 861-879. https://doi.org/10.5007/2175795X.2016v34n3p861

Selau, B., Damiani, M. F., \& Costas, F. A. T. (2017). Estudantes cegos na educação superior: o que fazer com os possíveis obstáculos? Acta Scientiarum, 39(4), 431-440. https://doi.org/10.4025/ actascieduc.v39i4.28915

Silva, L. V., \& Bego, A. M. (2018). Levantamento bibliográfico sobre Educação Especial e Ensino de Ciências no Brasil. Revista Brasileira de Educação Especial, 24(3), 243-358. https://doi.org/10.1590/ s1413-65382418000300003

Silva, M. R., \& Camargo, E. P. (2018). O processo de inclusão no Ensino Superior: relatos e reflexóes sobre a experiência de dois licenciandos em Física com deficiência visual na universidade. In G. S. Mól (Org.), Pessoas com deficiência no Ensino Superior (v. 2, pp. 100-111). Brasil Multicultural.

Silva, M. C. C. C., Barros, A. S. S., \& Silva, M. S. (2018). Turismo para cegos: old and new symbolisms in a literary work on blindness. Estudos de Literatura Brasileira Contemporânea, 54, 61-83. https:// doi.org/10.1590/10.1590/2316-4018544

Silva, K. C. D., \& Mól, G. S. (2018) Professores regentes de Ciências da Natureza na sala de aula inclusiva. In G. S. Mól (Org.), O ensino de Ciências na escola inclusiva (v. 2, pp. 117-131). Brasil Multicultural.

Silva, R. S., \& Mól, G. S. (2019). Educação Especial Inclusiva na formação continuada de docentes dos cursos de Licenciatura em Ciências: articulando saberes. In Mól, G. S. (Org.), O ensino de Ciências na escola inclusiva (pp. 69-185). Campo dos Goytacazes: Brasil Multicultural.

Uliana, M. R., \& Mól, G. S. (2017). O processo educacional de estudante com deficiência visual: uma análise dos estudos de teses na temática. Revista Educação Especial, 30(57), 145-162. https://doi. org/10.5902/1984686X20289

Vendramin, C. (2019). Repensando mitos contemporâneos: o capacitismo. Simpósio Internacional Repensando Mitos Contemporâneos, 2, 16-25.

Veraszto, E. V., Camargo, E. P., Miranda, N. A., \& Camargo, J. T. (2014). Professores em formação em ciências da natureza: um estudo acerca da atuaçáo de cegos congênitos em atividades científicas. Formaçâo Docente, 6, 69-86.

Vigotski, L. S. (1997). Tratado de defectologia, obras completas. Pueblo y Educación.

Vigotski, L. S. (2011). Defectologia e o estudo do desenvolvimento e da educação da criança anormal. Educação e Pesquisa, 37(4), 861-870. https://doi.org/10.1590/S1517-97022011000400012

Recebido em: 21/10/2020

Reformulado em: 01/02/2021

Aprovado em: 27/02/2021 